\title{
Wraparound as a Community Mental Health Service Philosophy for Children and Adolescents
}

\author{
Emarely Rosa-Davila, Ph.D, MSW ${ }^{*}$, Victor Lozada ${ }^{2}$ \\ ${ }^{1 *}$ Assistant Professor, Department of Social Work, Texas Woman's University, United States. \\ ${ }^{2}$ Doctoral Candidate, Department of Literacy and Learning, Texas Woman's University, United States.
}

Article Details
Article Type: Review Article
Received date: $20^{\text {th }}$ September, 2021
Accepted date: $25^{\text {th }}$ September, 2021
Published date: $02^{\text {nd }}$ October, 2021
$\quad$ *Corresponding Author: Emarely Rosa-Dávila, Ph.D, MSW, Assistant Professor, Department of Social Work, Texas
Woman's University, United States. E-mail: erosadavila@twu.edu
Citation: Rosa-Dávila, E. and Lozada, V. (2021). Wraparound as a Community Mental Health Service Philosophy for Chil-
dren and Adolescents. J Ment Health Soc Behav 3(2):147. https://doi.org/10.33790/jmhsb1100147
Copyright: C2021, This is an open-access article distributed under the terms of the Creative Commons Attribution License
4.0, which permits unrestricted use, distribution, and reproduction in any medium, provided the original author and source are
credited.

\begin{abstract}
Wraparound is a mental health services philosophy for children and adolescents. This philosophy includes a defined planning process that involves the child, adolescent, and family in making treatment decisions. As a result, it creates a unique set of individualized community services and natural supports to achieve multiple positive outcomes. This philosophy requires a work process that sometimes becomes uncomfortable for professionals in the mental health area since it takes us away from what we learned in the academy or what the agency we work expects us. This practice invites us to take off the hat of experts in our area of expertise. This article aims to present the Wraparound philosophy as an alternative for community mental health services at the tertiary prevention level for children and adolescents. Also, as an effective process in which communities learn to care for and protect their members by keeping them in the least restrictive environment.
\end{abstract}

Keywords: Community mental health, mental health, childhood and adolescence, social-community psychology, social work, Wraparound

\section{Introduction}

Even though some allege the contrary, it is my belief that when talking about mental health, one cannot separate people from the surrounding community. It is important to recognize the life history of a person who receives mental health services in order to intervene more effectively. When we talk about children and adolescents in Puerto Rico, we hear related commentaries that they are the future of our island. In the past, there have been campaigns such as "Nuestros niños/as primero [Our children first]" or "Haz de tus hijos/as tu mejor proyecto de vida [Make your children your best life project]" among others. These campaigns show that as adults we have to give the children the best example, to guide them on the good path.

Governmental institutions encourage parents to do all that they can for the good of their children. But, what happens when we talk about mental health? According to the Annual Report of the Administración de Servicios de Salud Mental y Contra la Adicción (ASSMCA) [Mental Health Administration and Addiction Services] from fiscal year 2009 , of the 7,163 children who received state mental health services, 6,122 were Medicaid beneficiaries, 722 had a private medical plan, 217 had no type of plan, and 102 did not provide information [1]. From this, one could interpret that the majority of these children came from families with limited economic resources as participants of Puerto Rican governmental health programs.
Currently in Puerto Rico, mental health services, mostly, are privatized. According to a report from the same agency, for fiscal year 2016-2017, a total of 1,401 adolescents and children were cared for at a variety of levels of service [2]. The most recent report shows that for fiscal year 2018-2019, 397 adolescents and children received services from la Clínica de Niños y Adolescentes de Río Piedras [Río Piedras Clinic for Adolescents and Children] [3]. In the mental health centers specializing in childhood and adolescence that still affiliate with ASSMCA, the people who work there are employed by the agency that makes them service providers from a private company in order to pay them for the services provided. Privatization of services means that people who cannot pay or do not have medical insurance, will not have access to essential health services [4]. It is important to add that even when offered, these services depart from the medical model, which means that the responsibility and control of the treatment of the patient resides with the mental health therapist; this in turn causes an imbalance in power, which resides with the mental health therapist [5].

It is my desire to emphasize through this work the services for children and adolescents who are severely emotionally disturbed. In my experience as a mental health professional, I see children and adolescents who are severely emotionally disturbed as a minority who are marginalized inside their peer groups. This does not only occur due to their emotional state. This happens because for a child who is severely emotionally disturbed, it is a challenge to control their behavior. With this, distinct parts of their lives can be seen as affected. The child or adolescent who is severely emotionally disturbed, many times, is the one who the teachers, even when trying, cannot manage control in the classroom; they are the ones who are not allowed to participate in summer camps because of their "behavioral problems." They are the ones who need more than medication to "function appropriately." They are the children and adolescents who need specialized mental health services that, currently, are not available in a systematized way in our country. The ASSMCA [6] defines minors who are severely emotionally disturbed as 1) having a mental health diagnosis that affects them for one year or more or that without care the condition continues to worsen, and 2) that this diagnosis affects their ability to function in two or more areas of life. Examples of these areas include family, school, community, and their physical health among others.

In Puerto Rico where the state has very few mental health centers for adolescents and children and where there is only one unit for psychiatric hospitalization for children, three for adolescents (two of which are private), and two residential treatment centers (one of 
which is private), how can we reach the point at which adolescents and children who are severely emotionally disturbed receive the services at the appropriate level of treatment they need? Family members of people who are severely emotionally disturbed need information and support to deal with the stress they experience [7]. Even more so, the traditional model of intervention does not consider the social context of the patient.

According to the World Health Organization (WHO, 2020), mental illness and injuries represent $16 \%$ of the worldwide population of people between 10 and 19 years of age. Additionally, they indicate that half of mental illness begins upon or before 14 years of age, but most mental illness is not detected then. This is important because when we talk about mental health during adolescence and childhood, we allude to the understanding that this population eventually catches up in regard to emotional indicators, developmentally, healthy social skills, and the ability to confront present problems (CDC, 2020). If the minor does not take into account good mental health or a mental health condition is not detected or treated timely, a possible consequence is that this illness continues into adult life and that the individual's physical health is also affected [8].

Given this background, the purpose of this paper is to explain the Wraparound philosophy as an alternative to community mental health services for adolescents and children who are severely emotionally disturbed. I intend to explain who one can utilize this philosophy of services from a Social-Community Psychology perspective. Nieves-Rolón and colleagues [9] published an article describing this philosophy and the fidelity process for monitoring the quality of services offered through the Wraparound in Puerto Rico. Contrasting this first paper, the specific objectives of this paper are:

- define the concept of mental health as described in this work;

- compare the values of Social-Community Psychology and the Wraparound;

- $\quad$ explain the philosophy of the Wraparound and its phases; and

- mention some barriers for implementation of the Wraparound.

\section{Mental Health}

WHO (2020) defines mental health as a state of wellbeing in which people can achieve their maximum potential, can deal with the normal stressors of life, work productively, and contribute to their community. If one conceptualizes mental health as an individual and/or group practice transformed from reality and related to selfawareness, the development of mental health implies a development of self-management and freedom for individuals and groups and the possibility of enacting a project that defends their genuine class or community interests [10]. Therefore, it is inconceivable to have a mental health process without the close collaboration between the individual and those who shared the same objectives and without taking into account the generalized benefits to everyone else, which result from the activities carried out.

Vilar and Eibengutz [11] point out that even though the final diagnosis of mental illness is determined subjectively, the psychiatric suffering is inscribed on a socially constructed subject whose history is determined by means that have been socially arranged for the fulfillment of desires. The profession of mental health is thankful for a subject to have the ability to design their own objectives and life work as well as the ability to gather the necessary resources to complete these projects. One does not reach these goals without the full participation of the subject in society. Thus, we are only able to stop mental illness and promote mental health if we can create ideal conditions in which (1) subjects can live in a state of wellbeing and can develop and carry out a life project that is produced and satisfying and in which (2) they have the right to an environment compatible with their health and the right to appropriate services when the illness manifests.

J Ment Health Soc Behav

Volume 3. 2021. 147
This suggested conception of mental health has its own characteristics and its own objectives. It is generated from the definition of the human being as a social being. Based on this, Rodríguez Rossi [10] presented positive indicators of mental health that contribute to a good review, collective work, and the development of common projects among individuals. Among these positive indicators based on this conception, I propose:

- Groupality: greater participation of the person in group decisions, with productive benefits that transcends the subjects own interests, and with greater autonomy to all groups with respect to decision-making;

- Use of free time: regarding free time for rest, necessary play time, regarding personal development and creativity, interactions among everyone else, and the increase in these type of activities;

- Creativity: with a predominance of divergent thinking, abstract, symbolic activities, and the social interaction that creates these activities; and

- Social consciousness: critical responses referring to individual, group, and social problems in general (pp. 110-111).

Pino [12] indicated that scientific studies have verified that the majority of people with mental health illness improve and many recover completely. Pino also demonstrated that having a productive life and the reduction or complete elimination of symptoms is what many consider full recovery. This is what we hope to achieve through the Wraparound philosophy, full recovery of adolescents and children who are severely emotionally disturbed, achieving that they stay in the least restrictive environment, which is the community.

\section{Values of Social-Community Psychology}

If we start at Social-Community Psychology, the Wraparound is a philosophy whose values are aligned with those of the discipline. To continue, I mention some values of the profession according to Serrano-García and colleagues [13] that compare elements of the Wraparound principles. One of the values of the discipline is the dilemma of change for social justice, which means providing social change at any level of social-community psychological treatment with the purpose of achieving equity in the distribution of social resources [13]. In regard to this paper, this refers to the resources that children and adolescents who are severely emotionally disturbed need to have accessible to them for the recovery process. Another of the values is establishing horizontal power relationships. This means that the social-community psychologist should share resources with the population they treat; they should not impose superiority. The psychologist's expert opinion is just as valid as the knowledge from the community. There are methodologies such as Participatory Action Research (PAR) that come from this point of view. PAR is "un método de investigación y aprendizaje collectivo de la realidad social [a research methodology and collective learning that comes from social reality]" [14] based on reflexive analysis in which the community as much as the social-community psychologist actively participate to promote transformational practice. There is an effort to remain as agents of social change, immersed in the realities of communities, to promote justice through PAR.

Additionally, there is the value of respect toward cultural relativity and diversity [13]. These authors defined this as the idea that there are no absolute truths nor are there correct values for everyone. Diversity is a place from which springs knowledge and improvement. Not only does it manifest itself in the community or country in which someone lives but also in the contributions of other countries and cultures. They added that community knowledge and its expressions are just as valid as those of scientists and experts.

Another value is the strengthening of civic engagement and the feeling of community. We should promote civic engagement in social 
affairs that encompasses active forms of democracy. This will contribute to the generation of a sense of belonging and solidarity [13]. The next value is the emphasis on primary prevention or the promotion of wellbeing. This is when strengths are emphasized rather than weaknesses; this is about attacking physical and mental health problems before they begin.

The last value of Social-Community Psychology that I would like to mention is the interdisciplinary approach to intervention. When developing interventions, one should consider the contributions of other disciplines in an integrated way [13]. These authors indicated that these values have prevailed for four decades even though they have not remained static.

\section{Philosophical Foundations of Wraparound}

When discussing Wraparound, we are referring to an organized way in which people from the community support other people that need help [15]. Psychologist Dr. Lenore Behar first used the term Wraparound in 1986 to describe an individualized system linked to the community [16]. She began using this term to describe the implementation of community-based services for institutionalized youth in North Carolina [17]. It is a philosophy that includes a defined planning process that includes the child or adolescent and their family and results in the creation of a unique series of individualized community services and natural supports that lead to multiple positive outcomes [18]. It is a process through which communities learn to take care of and protect their members [15].

Wraparound began as a strategy to describe services during the 1980 s in the United States. Currently, it is an evidence-based practice $[19,20]$. Although its formal beginnings are traced back to the 1980 s, it began much earlier. The history of civilizations and cultures from around the world have many diverse and complicated support methods for families and their members. Many societies have experience with providing formal services in diverse settings. National Geographic published an article that highlighted the principles of the Wraparound process. It was about the findings of a study about a man who had an accident which caused trauma to his bones and made it impossible for him to use survival skills such as hunting, personal hygiene, and feeding himself. With this, he was helped by his tribe and survived many more years with group support from his community [21]. This article demonstrated who this man could survive despite his accident thanks to the community's support.

VanDerBerg [22] defined the concept in a more theoretical form proposing that the important part of its foundations is that human beings prefer to live in community with their families, friends, and their chosen community. Additionally, he indicated that the needs of human beings are complicated in that they are better served with the support of other human beings. Because of human nature, the needs and how you are satisfied accomplish better and prolonged results if they are working from person to person [15].

During the 1990s, the Wraparound model was being used in many mental health programs for children and adolescents within the United States. Nevertheless, there was no formal agreement as to what exactly Wraparound was. Many of the programs that utilized it shared the elements of involving the child or adolescent and the importance of creating a network of community services and informal supports in their processes, yet there was no consensus about how to define the term [23]. Thus, by 1998 a group of people interested in coming to a consensus met to sketch out which were the essential elements to the Wraparound process [24]. I will present them in the following section.

\section{Essential Elements of Wraparound}

The first principle of this practice is the voice and choice of the child, adolescent, and the family $[9,23,25]$. This defines the process as an intentionally listening perspective, in which the work team listens to what the participant and their family say and choose. This team has the responsibility to offer options that reflect the values and preferences of the family and recognize the long-term connection among its members. Additionally, this implies that the choices the child or adolescent makes are influenced by the family to which they belong. When we listen to what the family wants and selects, the probability of success from the plan increases and those results are positive [26]. The options also increase and consensus is promoted because balance is achieved in the elected decisions.

The second principle is that Wraparound is based on teamwork $[9,23,25]$. These are groups of people who agree with each other and are committed to working with and for families. The family chooses the people who belong to these teams. Not all of the resources that a family uses have to be a part of the Wraparound team and not all of the team members have to physically attend meetings. Additionally, this team should include both formal and informal supports. To be considered a Wraparound team, at least $51 \%$ of the team should be comprised of informal supports [26] because just like the services, and like the team that works with the family, there is a beginning and an ending. This is with the hope that once the child or adolescent ends treatment, the informal supports remain in their lives, which help them remain healthy.

Formal and informal supports are the third principle of this practice $[9,23,25]$. The Wraparound model encourages the invitation of support resources from within the community. Part of this premise is that the activities and interventions of the plan increase when informal supports that help to maintain good relationships in the community exist. Additionally, the informal supports greatly influence family members' lives. For example, a child or adolescent can say that they want some of their school and community friends to be on their team. This practice necessarily promotes for the family to meet with the team independently with service provider representatives.

The fourth principle is that Wraparound is a collaborative activity $[9,23,25]$. The Wraparound team shares the responsibility of developing, implementing, monitoring, and evaluating the plan. This plan should reflect the perspective, desires, and resources of the team members. The team agrees upon the established goals. Wraparound is a process of collaborative planning that includes family members, service providers, the informal supports from the family, and their networks of support within the community [27].

The fifth principle is that Wraparound is based in the community $[9,23,25]$. This practice is defined as the team implementing support services and strategies from the community. This makes services more inclusive, more responsive, and more accessible. Look for maintaining the least restrictive environment for the child or adolescent. The challenge with this is that currently the options for community-based treatment many times are not available. Presently, the first option for an adolescent with a mental health crisis is hospitalization or residential treatment and not looking for alternatives that maintain the least restrictive environment [28], which is their home.

The sixth principle is that services be culturally competent [9, $23,25]$. Cultural competence implies that to be able to complete a good evaluation or assessment about the different situations that the families for which we care experience, we must know where they live, what are their customs and traditions, the historical moment in which the family resides when we are caring for them or when the situation arose that brought them to receive services. It is the respect of traditions, values, beliefs, preferences, culture, and the identity of the child, family, and their community. It deals with recognizing their strengths. The team should respect the diversity of the expression of opinions and preferences.

The Wraparound presents us with the seventh principle of individualized care $[9,23,25]$. Each child or adolescent and their 
family has distinct strengths and needs. Even when the situation that brought them to receive services is the same, the way in which the family interprets and approaches that reality can be distinct. This is why at all times the service plan should be individualized, adjusting to the needs of each family. This plan should include what is the goal of the family, the objectives of working in distinct areas of their life, and what are their strengths and needs. Similarly, it should also include services offered and coordinated, the utilized strategies, the available resources, and the date at which they can expect to achieve the objectives and/or goals. The service plan should capitalize on the collective strengths of the creativity and knowledge of possible strategies and resources. Upon offering or coordinating services, one should listen to what is the most pressing situation for the family and give it priority. This helps us to increase positive outcomes and the attainment of the goals. Being an individualized service, each team has its own rules [23].

The either principle is that services should be strengths-based $[9,23,25]$. This indicates that the Wraparound process identifies and constructs the capacities, knowledge, skills, access, and abilities of the child, the family, and the community. This principle changes the perspective from seeing situations from a need-based to a strengths-based perspective. All people, families, and communities have multiple strengths. In the beginning it is difficult for the family to focus on the positive. It is important to specifically validate the strengths with the purpose of constructing the service plan based on those strengths. By utilizing this way, one can achieve decreasing the impact of the areas of need. It is questioning what can this child or adolescent do with their strengths and convert them into action.

The ninth principle is persistence $[9,23,25]$. This refers to the persistence of the team to reach the goals together; goals that are realistic. This principle includes the idea that an unwanted behavior, event, or result is no evidence that the child and their family have failed. If an adverse event occurs from what the team had planned, it should be interpreted that the plan should be revised.

The tenth and final principle of Wraparound is that it be resultsoriented $[9,23,25]$. This is shown when the service plan is measurable and the goals and strategies are observable with clear indicators. Progress is monitored in terms of these indicators with an eye on revising the plan.

\section{Social-Community Psychology and Wraparound}

If we consider the previously mentioned values of SocialCommunity Psychology, we are able to visualize the relationships among the principles of Wraparound. I detail this comparison in Table 1.

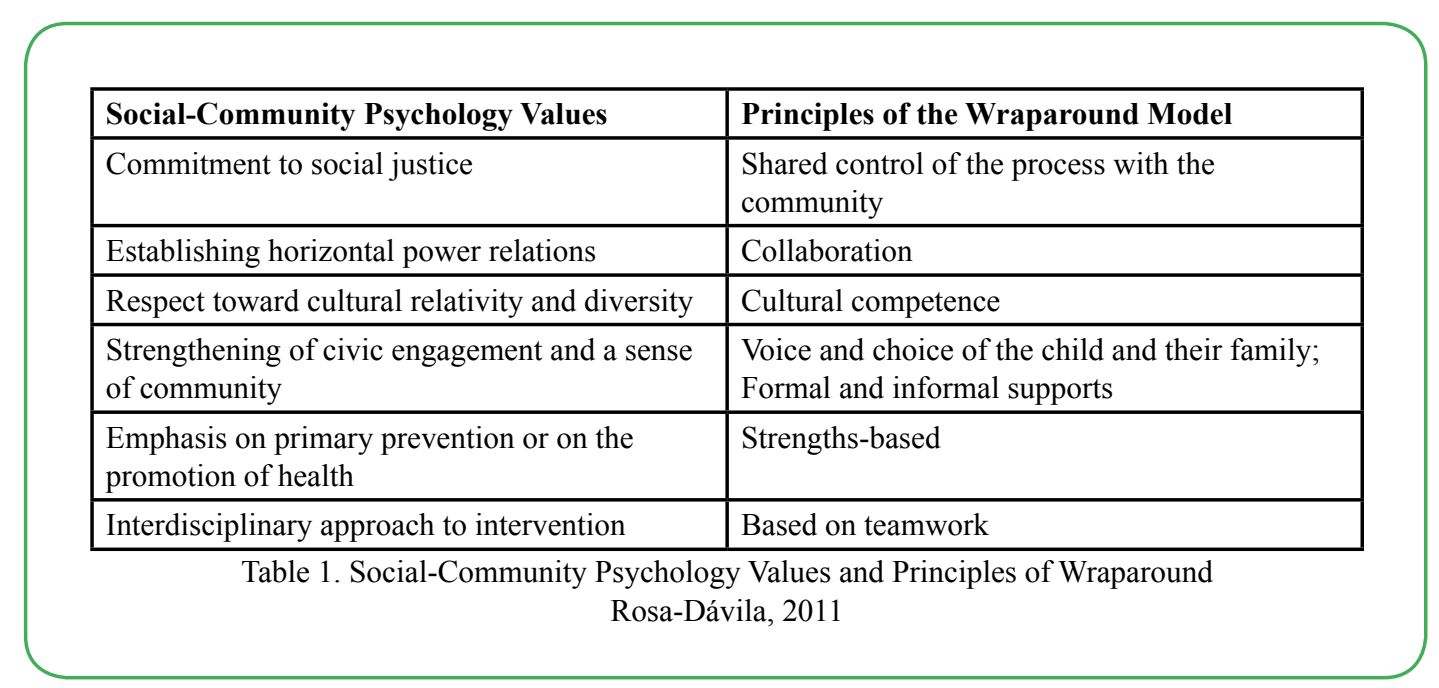

The philosophy of Wraparound defined by its ten principles expresses a simple vision that appeals to our senses. When a child or adolescent suffers from a severe mental condition, their family also suffers from it and looks for the ability to access appropriate service and support that maintains security, togetherness, and that allows them to continue functioning in the activities in their daily lives.

After explaining the principles of this practice, the reader will ask, "What is the difference?" One may think that these principles are not new. This is correct. What differentiates Wraparound from other forms of intervention is that the team "belongs" to the child, adolescent and their family while in the medical model the team leader is the therapist or professional. Additionally, the development of individualized plans allows for one to work in multiple situations. For example, one can work with the child as a person, the child as part of their family, in school, in the community, their physical health, and legal aspects among other systems that are part of the child or adolescent's life. In the medical model, the search for health centers on the patient-therapist relationship [5]. Additionally, as previously mentioned, the service plan is strengths-based.

In this practice, the family guides the process, who are integrated into all of the networks of the system that are necessary.
We can see this as a form of the interagency coordination of services in Puerto Rico. For example, a parent arrives requesting services for their child because they know that their child has problems. If upon initial screening the professional understands that they meet the criteria for being identified as someone who is severely emotionally disturbed, the professional identifies which functional areas of the child's life are affected. Then, suppose that the child continues to have problems at school, stays in the Special Education program, that the family has an active case with the Department of Family, that they are receiving psychological or psychiatric treatment yet still the difficulties continue. As is current practice in Puerto Rico, each agency that offers services has a different treatment plan. In this situation, when working with the Wraparound model, the professionals that would work with the minor would be a part of the Wraparound team. Therefore, in the present situation, the child would have four distinct service plans. In order to work the plans in an interagency way, the Wraparound team meets to create one care plan that includes all of the needed areas for the child and their family. Hence, all of the agencies and informal supports come together for the benefit of the minor and their family. In this way, everyone works toward the same goal with the fragmentation of services. Interdisciplinary work 
improves the results of the services offered and the level of participant satisfaction [29,30]. Additionally, it avoids the duplication of services leading to a more comprehensive coordination of care [31]. This requires for each professional to respect the work of the other professionals in their respective agencies.

One of the differences between the Wraparound model and the medical model is that it requires a change in perception of needs and services. It also requires that the family takes ownership of their recovery process [32]. It requires that the professional accepts a horizontal power relationship; that they depart from the role as the expert learned throughout academia. Additionally, it is necessary that the family actively participates in all decision-making processes. In order to do this, it is important to educate and empower the family in the decision-making process because no one understands the problem better than the affected family. The empowerment of the family to take over their decision-making process can take time and has barriers. Mostly, this is because when we talk about healthrelated services in Puerto Rico, it begins from the medical model, from the needs of patient and not from their strengths, and from a power relationship in which the professional has control.

Another question that the reader might ask is how we can differentiate between the Wraparound model and the medical model, which as previously explained, dominates those services offered in Puerto Rico. Wraparound focuses on the family. The medical model focuses on the professional who offers services [5]. McWhirter [33] raised the comparison that I present in Table 2.

\begin{tabular}{|l|l|}
\hline Professional centered & Family centered \\
\hline Professionals determine the necessary work & Families identify their needs \\
\hline $\begin{array}{l}\text { Higher level of decision-making falls on the } \\
\text { family }\end{array}$ & \\
\hline Families as deficits (needs-based) & Families have strengths \\
\hline Services designed to fix the deficits & $\begin{array}{l}\text { Services focused on continuing to strengthen } \\
\text { the families }\end{array}$ \\
\hline $\begin{array}{l}\text { Accommodate the family to the services } \\
\text { offered }\end{array}$ & $\begin{array}{l}\text { The services accommodate to what the family } \\
\text { needs }\end{array}$ \\
\hline Focused on solving problems & Focused on developing abilities \\
\hline Roles and services that are relatively fixed & Flexible roles and services \\
\hline
\end{tabular}

Wraparound requires looking at current family issues in a radically different way. In the medical model approach, the clinician is the expert who diagnoses the problem and solves it. The child or adolescent is the patient who receives services (Brown University, 2002). Wraparound involves the creation of a team that includes supports but that may or may not include experts in different fields. The child and the family define the goals and collaborate in the planning of community-based strategies. These solutions are holistic, flexible, and strengths-based (Brown University, 2002).

\section{Implementation Phases for Wraparound}

Being a family-centered practice, the process is guided by four phases that ensure this aspect. The first phase is based on the preparation of the Wraparound team [9,34]. Here the family is oriented to what the Wraparound process is and to the legal and ethical issues that apply, which I will discuss later. Additionally, if there is a crisis, it stabilizes. Obtaining information from family members, the agencies where the child or adolescent receives services, and potential team members is important. In this phase, in conversation with the family, they explore what the strengths, needs, culture, and vision for life are and prepare a document with these notes. Later, they explore who can be members of this team, and, with the permission of the family, they are contacted to orient them to the process and invite them to participate. The phase ends when an agenda for the next needed meetings for the process is prepared.

The second phase is the development of an initial plan [9,34]. At this time, it is determined what are the rules for the process. These may include how the team will make decisions. For example, it might include if the agreements and decisions will be done by a simple majority or if the child or adolescent will receive two votes. The initial plan begins with what is the goal of the family and of the team and describes the strengths of the child or adolescent and their family.
Additionally, needs and objectives are described and prioritized. The expected outcomes and how they will be measured are determined by choosing strategies and assigning tasks. A crisis intervention plan is created to minimize risk and to know how to respond to possible emergencies. For this, past crises that the child or adolescent has had or possible crises that the family anticipates are explored to prepare a crisis intervention plan with this information. Finally, the necessary documentation is completed.

The third phase is the implementation of the plan [9,34]. With this, the steps to arrive at expressed strategies in the care plan are put into action. Additionally, progress is observed, which strategies have been successful is evaluated, and achievements accomplished at the moment are celebrated. If necessary, the care plan is revised and updated taking into consideration new strategies. It is important to continue to maintain or build unity among the Wraparound team and stay abreast of whether the team is satisfied with the progress or not. If there are any disagreements or conflicts in the team, it is important to work them out.

The last phase is the transition [9, 34]. Even though this is the last phase, the reality is that transition is worked on from the first phase since it is important that the family knows that this process is temporary and has a beginning and an end. In this phase, work is done so that formal supports from the team begin to diminish. A transition plan and a crisis intervention plan are created for after the transition. A meeting is held in which the work of the Wraparound team is documented and compared and achievements of the family and team are celebrated. As part of the transition, there is a followup period after the end of services. This can be between three to six months.

Working through these phases with children and adolescents who are severely emotionally disturbed can take between six months and two years of intensive services. That is to say that the child or adolescent receives services weekly. It does not mean that the team meets 
every week. That is determined by the participants. In each phase of the process, different types of professionals contribute. In some cases, the psychologist may function as the facilitator of the Wraparound team.

\section{Barriers to the Implementation of Wraparound}

If we can apply the Wraparound philosophy to our work with child and adolescent mental health, we can use it to help children who are severely emotionally disturbed. Nevertheless, it is important to mention some barriers found in the implementation of this model. McGinty and colleagues [35] pointed out that the lack of support from coworkers and supervisors can affect the work of the person coordinating Wraparound services. They added that some of the things that coworkers who oppose the process say are, "I've already done that," "They didn't hire me to do that," "I don't have the time," "We are losing control of clinical matters," "It is different from what we do here," or "We have to share responsibility with others." Therefore, unless all members of the organization are trained in the Wraparound model, it will be very difficult to use with families.

Another barrier that they mention is that although generally people who reside within a community are willing to cooperate, the difficulties come from the lack of knowledge about Wraparound and the difficulty of finding ways to promote it within the community. If the community is rural, this barrier is even greater [35]. Also, many community leaders are involved in other projects which leaves them little time to participate in this initiative.

In agreement with McGinty and her colleagues [35], for the mental health agency, Wraparound represents a way of providing services and requires a programmatic transition that can be difficult and challenging. Additionally, it requires that staff go through an initial and recurring training process to achieve sustained change in the services that they offer. The support of agency administrators is vital for this change. It is my belief that although the Wraparound process motivates us to build local resources, it is important to understand that service can be obtained, occasionally, but not always, free.

I understand that the level of public policy is the greatest barrier. Financial and legal restrictions, a rigid bureaucracy, and the differences in the institutional policies of our agencies can bring obstacles to interagency collaboration. The difficulty of matching this type of service with the forms required in each agency plus what is added by the Wraparound process can complicate the functionality of the service. With this, the complexity of implementing the wraparound process and maintaining focus for a long time can lead to poor implementation and little support from agencies and the community, which affects the quality of interventions [35].

\section{Final Reflection}

Wraparound demands a work process that occasionally results in some professionals being uncomfortable since it takes away from what was learned in university or what the agency at which we work expects from us. This practice invites us to take off our hat as experts of our specialized field and to work hand-in-hand with families who are the ones who know their needs best. Being accustomed to working from the medical model, many times we focus only on identifying the areas of need for our clients. We are not accustomed to deeply exploring what their strengths are beyond those indicated at the initial interview. We cannot limit ourselves to identifying the strengths of children, adolescents, and their families. We need to give the strengths a function that we can turn action into work for the benefit of the areas of need. We need to move ourselves to a more positive model that gives us hope, a model that makes sense for children and adolescents who are severely emotionally disturbed. A model in which the last option is hospitalization or institutionalization, which gives the child or adolescent the opportunity to stay with their community. As community agents, we are the ones who have to make these changes. It is from the need for services for children and adolescents who are severely emotionally disturbed, and from their real demands that we can build a probable and feasible space for action [36]. We specialists are mediators and facilitators of these actions, but we never substitute the role that corresponds to these actors.

Conflict of interests: The authors declare no conflict of interest. References

1. ASSMCAb (2009, septiembre). Informe anual de logros. San Juan, Puerto Rico: Estado Libre Asociado de Puerto Rico.

2. ASSMCAc (2020, febrero). Informe anual de logros año 20162017. San Juan, Puerto Rico: Estado Libre Asociado de Puerto Rico.

3. ASSMCAd (20020, octubre). Informe anual de logros año 2018-2019. San Juan, Puerto Rico: Estado Libre Asociado de Puerto Rico.

4. Serrano-García, I., Gorrín Peralta, J.J. (1998). La estructura y organización de los servicios de salud/enfermedad: otro reto para el modelo biopsicosocial. En I. Serrano-García, M. Bravo, W. Rosario- Collazo \& J.J. Gorrín Peralta (Eds) La psicología social comunitaria y la salud: Una perspectiva puertorriqueña (74-109). Publicaciones Puertorriqueñas.

5. Montero, M. (2009, junio). Del enfoque psicosocial comunitario al enfoque clínico comunitario: Situar la praxis en América Latina. Conferencia presentada en el XXXII Congreso Interamericano de Psicología Ciudad de Guatemala, Guatemala.

6. ASSMCAa (2006, febrero). Informe anual de logros. San Juan, Puerto Rico: Estado Libre Asociado de Puerto Rico.

7. Lucksted A., Stewart, B. , \& Forbes, C. (2008). Benefits and changes for family to family graduates. American Journal of Community Psychology, 42, 154-166. https://doi.org/10.1007/ s10464-008-9195-7

8. Organización Mundial de la Salud. (2020). WHO urges more investments, services for mental health. https://www.who.int/ mental_health/who_urges_investment/en/

9. Nieves-Rolon, I. E., \& Rosa-Davila, E., Fuentes, Ch. \& Vélez, C (2015). Wraparound: Una opción efectiva para el ofrecimiento de servicios de salud mental a menores en Puerto Rico. Ámbito de Encuentros, 8 (1), 37-51. Recuperado de http://www.suagm. edu/une/pdf/ambito/ambito_8_1.pdf

10. Rodríguez-Rossi, R. (2005). El hombre como ser social y la conceptualización de la salud mentalpositiva. Investigación en salud, 7, (2), 105-111. https://www.redalyc.org/ pdf/142/14270205.pdf

11. Vilar Preyil, E. \& Eibengutz Hartman, C. (2007). Migración y salud mental: Un problema emergente de salud pública. Revista Gerencia, Política, Salud, 6 (13), 11-32. https://www.redalyc. org/pdf/545/54501301.pdf

12. Pino, A. (2010, 1 de noviembre). No estoy loco. El Nuevo Día. p.16.

13. Serrano-García, I, Carvallo Messa, V. \& Walters Pacheco, K. (2009). Reflexiones sobre valores en psicología comunitaria: Adiestramiento ¿para qué?. En F. Cintrón Bou, E. Acosta Pérez \& L. Díaz Meléndez Psicología comunitaria: Trabajando con comunidades en las Américas. (págs. 227-254). Publicaciones Puertorriqueñas.

14. Benítez-Eyzaguirre, L. \& Iglesias-Onofrio, M. (2017). La metodología investigación-acción participativa aplicada al proyecto-balance y resultados. En: Género, Tecnología e innovación social: una experiencia de Investigación-AcciónParticipativa en Marruecos (pp.166-183). Universidad de Cádiz https://www.researchgate.net/publication/325531392_ La_metodologia_investigacion-accion_participativa_aplicada_ al_proyecto-balance_y_resultados 
15. VanDenBerg, J. E. \& Grealish E. M. (1996). Individualized services and supports through the wraparound process: Philosophy and procedures. Journal of Child and Family Studies, 5, 7-21. https://doi.org/10.1007/BF02234675

16. Wyles, P. (2007). Success with Wraparound: A collaborative, individualized, integrated and strength-based model. Youth Studies Australia, 26 (4), 45-53. http://hdl.voced.edu. au/10707/184882.

17. Behar, L. (1985) Changing patterns of state responsibility: A case study in North Carolina. Journal of Clinical Psychology, 14, 88-195. https://doi.org/10.1207/s15374424jccp1403_4

18. Burns,B.(1999). A call for mental health services research agenda for Routh with serious emocional disturbance. Mental Health Services Research 1, 510. https://doi. org/10.1023/A:1021927100830

19. Hoagwood, K., Burns, B., Kiser, L., Ringsein, H. \& Schoenwald, S. (2001). Evidence based practice in child and adolescent mental health services. Psychiatry Services, 52 (9), 1179-1189. https://doi.org/10.1176/appi.ps.52.9.1179

20. Bruns, E. \& Ferris, A. (2018, July 25). Implementing Evidence Based Practice within Wraparound and Systems of Care. Conference offered at the 2018 Childrens Behavioral Health Training Institues: Washington DC. https://depts.washington. edu/wrapeval/sites/default/files/presentations/13.\%20Wrap $\% 20$ -\%20ЕВP\%20for\%20institutes\%20EB\%206-20-18\%20 version.pdf

21. Parfit, M. (2000). The dawn of humans. National Geographic. Recuperado en http://ngm.nationalgeographic.com/ngm/0012/ feature3/fulltext.html

22. VanDenBerg, J. (1993). Integration of individualized services into the system of care for children with emotional disabilities. Administration and Policy in Mental Health, 14, 23-23. DOI: 10.1007/BF0070735

23. Walker, J. \& Bruns, E. (2006) The Wraparound process: Individualized, community-based care for children and adolescents with intensive needs. En J. Rosenberg \& S. Rosenberg (Eds) Community Mental health: Challenges for the 21th century. New York. Routledge. https://depts.washington. edu/wrapeval/sites/default/files/publications/The $\% 20$ wraparound $\% 20$ process $\% 20$ Individualized $\% 20$ commun.pdf

24. Burns, BJ., Goldman, SK. (Eds.) (1999). Promising practices in Wraparound for children with serious emotional disturbances and their families. Systems of care: Promising practices in children mental health 4 p. 95-113. American Institute for Research. https://files.eric.ed.gov/fulltext/ED429422.pdf

25. Bruns, E., Walker, J., Adams, J., Miles, P., Osher, T., Rast, J., VanDenBerg, J. \& NationalWraparound Initiative Advisory Group (2004). Ten principles of the Wraparound process. Portland, OR: NationalWraparound Initiative, Research and Training Center on Family Support and Children's Mental Health, Portland State University. https://nwi.pdx.edu/pdf/ TenPrincWAProcess.pdf

26. Pullmann, M. (2009). Participatory research in systems of care for children's mental health. American Journal of Community Psycholog, 44, 43-53. https://doi.org/10.1007/s10464-0099245-9

27. Bruns, E., Rast, J., Peterson, C., Walker, J., \& Bosworth, J. (2006). Spreadsheets, service providers, and the statehouse: Using data and the wraparound process to reform systems for children and families. American Journal of Community Psychology 38, 201-212. https://doi.org/10.1007/s10464-0069074-z

J Ment Health Soc Behav

Volume 3. 2021. 147
28. Ley 408 (2 de octubre de 2000). Ley de salud mental de Puerto Rico. Leyes de Puerto Rico, parte 3, p. 2664-2811. http://www. lexjuris.com/lexlex/Leyes2000/lex2000408.htm

29. Fewster-Thuente, L. \& Velsor-Friedrich, B. (2008). Interdisciplinary collaboration for healthcare professionals. Nursing Administration Quarterly, 32(1):40-48. DOI: 10.1097/01.NAQ.0000305946.31193.61

30. Youngwerth, J. \& Twaddle, M. (2011). Cultures of interdisciplinary teams: how to foster good dynamics. Journal of Palliative Medicine, 14(5):650-654. DOI: 10.1089/ jpm.2010.0395.

31. Jacob A, Roe D, Merrigan R \& Brown T 2013, 'The Casey Allied Health Model of Interdisciplinary Care (CAHMIC): Development and implementation', International Journal of Therapy \& Rehabilitation, 20(8):387-395. https://doi. org/10.12968/ijtr.2013.20.8.387

32. Piipo J., \& Aaltonen, J. (2004). Mental health: Integrated network and family-oriented model for co-operation between mental health patients, adult mental health services and social services. Journal of Clinical Nursing, 13, 876-885. https://doi. org/10.1111/j.1365-2702.2004.00958.x

33. McWhirter, D. (2005, junio). Advance Wraparound skills building. Presentación ofrecida como parte del San Diego Wraparound Training Series. San Diego, California

34. Walker, J., Bruns, E., VanDenBerg, J., Rast, J., Osher, T., Miles, P., Adams, J \& NationalWraparound Initiative Advisory Group (2004). Phases and activities of the Wraparound process. Portland OR: NationalWraparound Initiative, Research and Training Center on Family Support and Children's Mental Health, Portland State University. https://www.co.lucas.oh.us/ DocumentCenter/View/9695/PhaseActivWAProcess?bid

35. McGinty, K., McCammon, S. \& Koeppen,V.(2001). The complexities of implementing the Wraparound approach to service provision:A view from the field. Journal of Family Social Work, 5 (3), 95-110. DOI: 10.1300/J039v05n03_07

36. Calviño, M., (2004). Acción comunitaria en salud mental: Multiplicadores y multiplicandos. Revista Cubana de Psicología, 21 (1), 37-44. https://go.gale.com/ps/anonymous?id $=$ GALE $\% 7 C A 146348013 \&$ sid $=$ googleScholar $\& \mathrm{v}=2.1 \& \mathrm{it}=\mathrm{r} \& 1$ inkaccess $=$ abs $\&$ issn $=02574322 \& \mathrm{p}=\mathrm{AONE} \& \mathrm{sw}=\mathrm{w}$ 